\title{
Intrinsic ZnO/Al-doped ZnO Homojunction: Structural and Optical Properties
}

\author{
A.S. Ismail ${ }^{1}$, M.H. Mamat ${ }^{2}$, M.F. Malek ${ }^{3}$, M.M. Yusoff ${ }^{4}$, N.D. Md. $\operatorname{Sin}^{5}$, S.S. Shariffudin ${ }^{6}$, \\ A.S. Zoolfakar ${ }^{7}$, A.B. Suriani ${ }^{8}$, M.K. Ahmad ${ }^{9}$, I. B. Shameem Banu ${ }^{10}$, and M. Rusop ${ }^{11}$ \\ 1,2,3,4,5,6,7,11 NANO-ElecTronic Centre (NET), Faculty of Electrical Engineering, Universiti Teknologi MARA (UiTM), \\ 40450 Shah Alam, Selangor, Malaysia \\ ${ }^{2,3,11}$ NANO-SciTech Centre (NST), Institute of Science (IOS), Universiti Teknologi MARA (UiTM), \\ 40450 Shah Alam, Selangor, Malaysia \\ ${ }^{8}$ Nanotechnology Research Centre, Faculty of Science and Mathematics, Universiti Pendidikan Sultan Idris (UPSI), \\ 35900 Tanjung Malim, Perak, Malaysia \\ ${ }^{9}$ Microelectronic and Nanotechnology - Shamsuddin Research Centre (MiNT-SRC), Faculty of Electrical and Electronic \\ Engineering, Universiti Tun Hussein Onn Malaysia (UTHM), Batu Pahat, Johor, Malaysia \\ ${ }^{10}$ Department of Physics, B.S. Abdur Rahman University, Vandalur, Chennai 600 048, India
}

\begin{tabular}{l} 
Article Info \\
\hline Article history: \\
Received Jun 1, 2018 \\
Revised Jul 10, 2018 \\
Accepted Jul 25, 2018 \\
\hline
\end{tabular}

Keywords:

Homojunction

Immersion

Structural Properties

Zinc Oxide

\begin{abstract}
Intrinsic zinc oxide $(\mathrm{ZnO}) / \mathrm{Al}$-doped $\mathrm{ZnO}$ ( $\mathrm{AZO}$ ) homojunction film was prepared using two-step immersion processes. The film was characterized using field emission scanning electron microscopy, X-ray diffraction (XRD), Raman spectroscopy, and ultraviolet-visible spectrophotometer to investigate their structural and optical properties. The surface morphology image displays that the $\mathrm{ZnO}$ deposited on the nanorod surfaces in layer form with average diameter of nanorods about $95 \mathrm{~nm}$. The structural properties of XRD pattern demonstrate that the film possessed good crystallinity with the preferred orientation at (002) plane. The film also possessed excellent absorption in the ultraviolet (UV) region with optical band gap energy of $3.22 \mathrm{eV}$. These results indicate that the film has a good potential for opticalbased device such a UV sensor.
\end{abstract}

Copyright $@ 2018$ Institute of Advanced Engineering and Science. All rights reserved.

\section{Corresponding Author:}

M.H. Mamat,

NANO-ElecTronic Centre (NET), Faculty of Electrical Engineering,

Universiti Teknologi MARA (UiTM),

40450 Shah Alam, Selangor, Malaysia.

Email:mhmamat@salam.uitm.edu.my

\section{INTRODUCTION}

Zinc oxide $(\mathrm{ZnO})$ is an n-type which is used in various applications include sensors, solar cells, light emitting diodes, and transistors [1-4]. These wide applications are benefited from its properties such as wide bandgap energy, non-toxic, low cost, and also able to be produced into nanoscale structures. Previous studies reported that $\mathrm{ZnO}$ can be produced into various kinds of nanostructures such as nanowires, nanorods, nanospheres, nanoflowers, and nanoflakes. However, one-dimensional structures (nanorod and nanowires) are more promising in device fabrications due to ease of electron transfer and reducing grain boundaryrelated defect [5]. To date, there are lots of fabrication methods that are used to produce $\mathrm{ZnO}$ nanostructures such as metal organic chemical vapour deposition (MOCVD), sputtering, electrodeposition, thermal chemical vapour deposition, and hydrothermal [6]. Among the fabrication methods, water-based preparation is favourable due to simple process and low temperature use. Besides, this method also capable of producing high quality nanostructure films, comparable to the methods which use high temperature and high vacuum conditions. 
Based on the previous studies, intrinsic $\mathrm{ZnO}$ coating, forming whether homojunction or heterojunction, manage to improve the properties of a film. According to Mamat et al., by coating $\mathrm{ZnO}$ nanorod arrays with intrinsic $\mathrm{ZnO}$ manage to improve the ultraviolet (UV) sensing performance due to the reduction of dark current [7]. In other study, Jiang et al. reported that the efficiency of $\mathrm{CuIn}_{1-\mathrm{x}} \mathrm{Ga}_{\mathrm{x}} \mathrm{Se}_{2}$ (CIGS) solar cells improved after coated with intrinsic $\mathrm{ZnO}$ [8]. In this study, we investigated the effect of $\mathrm{ZnO} / \mathrm{Al}$ doped $\mathrm{ZnO}(\mathrm{AZO})$ homojunction film in term of structural and optical properties. To the best of our knowledge, detail discussion on such homojunction film is rarely reported. The understanding on their properties is crucial for future implementation in devices.

\section{RESEARCH METHOD}

The preparation of $\mathrm{ZnO} / \mathrm{AZO}$ film involved three steps. First is a seed layer preparation. The detail preparation of seed layer has been reported in previous study [9]. For the preparation of AZO, zinc nitrate hexahydrate $(0.1 \mathrm{M})$, hexamethylenetetramine $(0.1 \mathrm{M})$, and aluminum nitrate nonahydrate $(0.001 \mathrm{M})$ were used as the main materials. The reagents were combined and then going through sonication process for 30 $\min \left(50{ }^{\circ} \mathrm{C}\right)$. Then the solution was stirred for $3 \mathrm{~h}$, followed by immersion to grow the nanorod array structures. Finally, the film was annealed for $1 \mathrm{~h}\left(500{ }^{\circ} \mathrm{C}\right)$. Then, the second immersion for homojunction layer was conducted by mixing zinc nitrate hexahydrate $(0.02 \mathrm{M})$ and hexamethylenetetramine $(0.02 \mathrm{M})$. Similar processes involving sonication, stirring, immersion, and annealing were used, where every parameters for each step were maintained. The illustration for the $\mathrm{ZnO} / \mathrm{AZO}$ homojunction film preparation is depicted in Figure 1. For structural analyses, field emission scanning electron microscopy (FESEM, JEOL JSM-7600F), X-ray diffraction (PANalytical X'Pert PRO), and Raman spectroscopy (Horiba Jobin Yvon-79 DU420A-OE-325) measurements were conducted. For optical characterizations, ultraviolet-visible (UV-vis) spectrophotometer (Varian Cary 5000) was used.

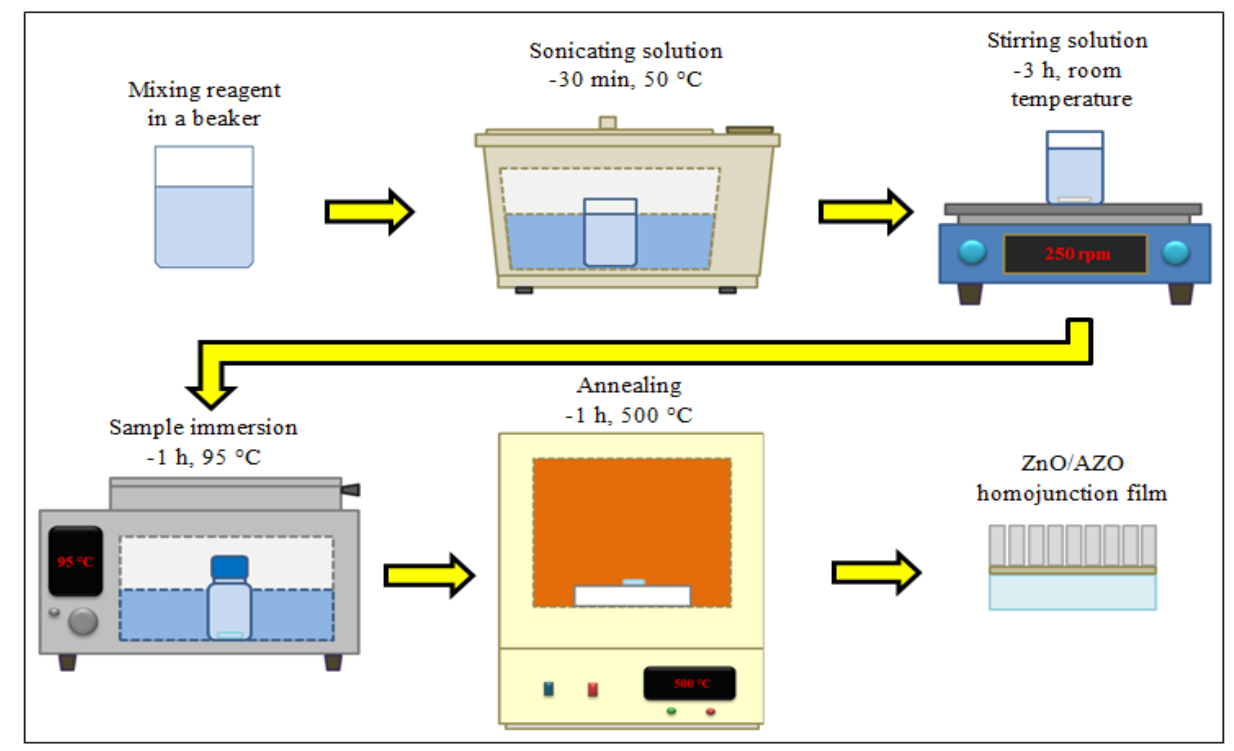

Figure 1. The illustration for the $\mathrm{ZnO} / \mathrm{AZO}$ homojunction film preparation

\section{RESULTS AND ANALYSIS}

The FESEM images in Figure 2 depict the surface morphology of the prepared samples. The images were taken at 100,000 $\times$ magnifications. Figure 2(a) shows the surface morphology of granular $\mathrm{ZnO}$ seed layer film. The average diameter of the grain is about $25 \mathrm{~nm}$. Figure 2(b) demonstrates the AZO film grown on the $\mathrm{ZnO}$ seed layer film. The average diameter of the nanorods is about $70 \mathrm{~nm}$. It is observed that the film consist of large pore areas in between the nanorods. Figure 2(c) depicts the $\mathrm{ZnO}$ film (0.02 $\mathrm{M}$ solution concentration) which was grown on the seed layer film. It is witnessed that only small part of the film is covered by the nanorods. Besides, the diameter of the nanorods is relatively small compared to AZO film, about $35 \mathrm{~nm}$. Other than that, we also observed nanoflake structure appears on the film in addition to the nanorod structures. Figure 2(d) displays the $\mathrm{ZnO} / \mathrm{AZO}$ homojunction film. Compared to the bare AZO film, 
it is witnessed that the nanorod arrays of $\mathrm{ZnO} / \mathrm{AZO}$ is covered by a slightly light color layer, which is intrinsic $\mathrm{ZnO}$. The average diameter of the film is about $95 \mathrm{~nm}$. Based on the image, it is indicates that the deposition of the intrinsic homojunction layer begin from the side surface, follows by the deposition on the top of the nanorods. This is based on the observation from the FESEM images that shows the less coverage of the intrinsic layer on the top surface of the nanorods. Interestingly, the growth process of the intrinsic $\mathrm{ZnO}$ does not develop into any form of nanostructures, but a layer. Such formation occurs may be due to the same crystal structure of $\mathrm{ZnO}$ and $\mathrm{AZO}$, which enhances the homoepitaxy growth on the previous crystal (AZO).

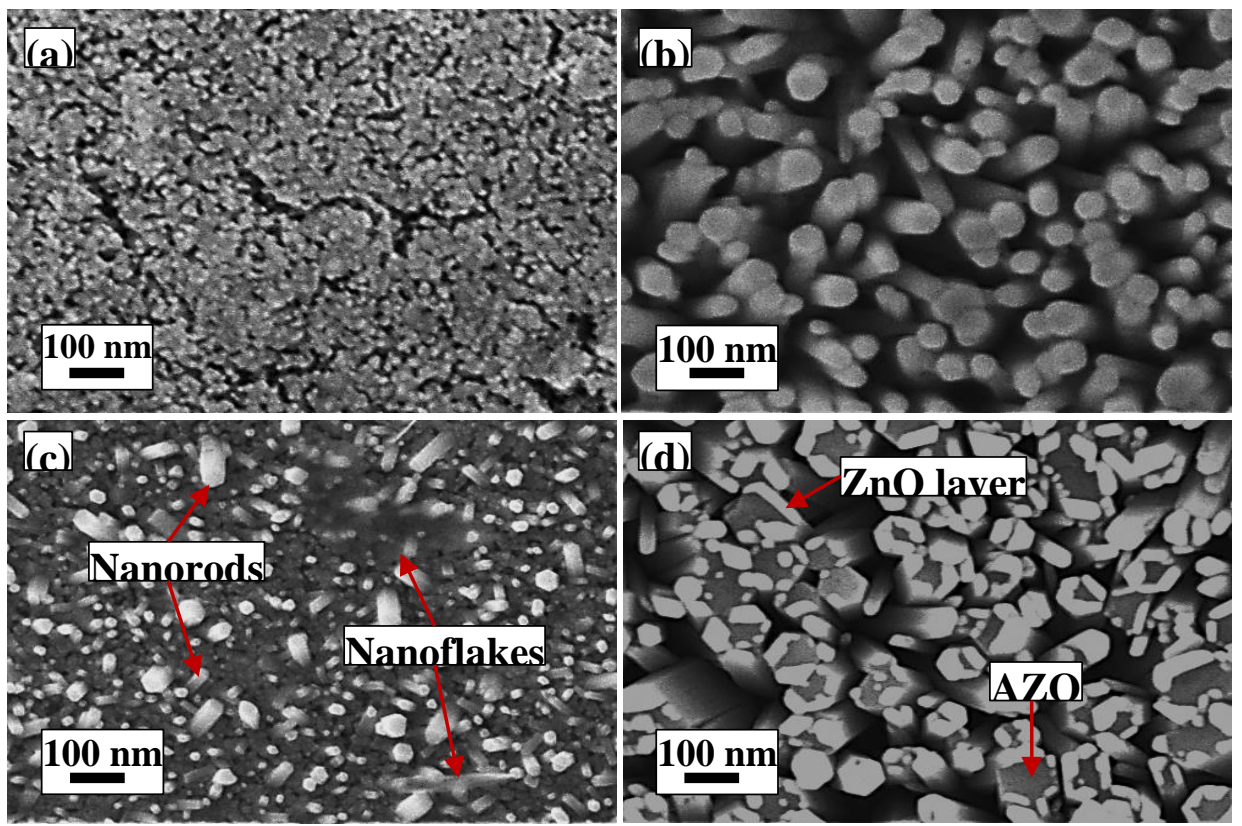

Figure 2. Surface morphology of (a) seed layer, (b) AZO, (c) ZnO, and (d) ZnO/AZO films at 100,000 × magnifications

Figure 3 depicts the XRD pattern of the synthesized films. The diffraction angles measured are from $25^{\circ}$ to $60^{\circ}$. The XRD pattern of each film is plotted individually and the intensity of the X-ray is shown in count-per-units (cps) to show the different in the intensity of each film. From the plots, there are several peaks occurred on the pattern, namely; (100), (002), (101), (102), and (110). For AZO film (Figure 3(a)), the dominant diffraction peak is at (002) plane orientation (along $c$-axis). For intrinsic ZnO film (Figure 3(b)), the dominant peak is at (100) and (101) plane orientations. Meanwhile, the growth of $\mathrm{ZnO} / \mathrm{AZO}$ film also exhibits a preferential growth along $c$-axis (Figure 3(c)). In case of $\mathrm{ZnO}$ film, the preferential crystal growth may be dominated by the seed layer film and small number of nanoflake structures (from FESEM images), which preferentially grown along (100) and (101) plane orientations. Once the ZnO layer is grown on the AZO, we can observe that the peak intensity at (100) and (002) slightly increased. The increment of preferential $a$-plane growth may explain the formation of layer on the AZO surface which is expected to originate from the side surface of the nanorods of the AZO film as discussed earlier. Figure 3(d) depicts the magnified image of the XRD patterns at (002) plane orientations. The plot shows the significant increases of peak intensity for the film which was grown with AZO. Comparing both AZO and ZnO/AZO films, only a slight increment to the peak intensity can be detected. Interestingly, no peak shifting can be witnessed after the second growth process, indicating no residual stress forced on the $\mathrm{ZnO} / \mathrm{AZO}$ film.

To investigate more on the crystal structure, we characterized the films using Raman spectroscopy as shown in Figure 4. The characterization was done under argon (Ar) laser operating at $514 \mathrm{~nm}$ as excitation source. Two inherent Raman peaks at 437 and $581 \mathrm{~cm}^{-1}$ which correspond to $\mathrm{E}_{2}$ (high) and $\mathrm{E}_{1}(\mathrm{LO})$ mode, respectively [10]. Other insignificant peak can also be observed which situated at $332 \mathrm{~cm}^{-1}$, which represents $2 \mathrm{E}_{2}(\mathrm{M})$ mode [11]. $\mathrm{E}_{2}$ (high) mode indicates the Raman vibration of hexagonal $\mathrm{ZnO}$ structure and the intensity of Raman vibration of $\mathrm{E}_{2}$ (high) increased which shows that better crystalline structure of AZO and $\mathrm{ZnO} / \mathrm{AZO}$. This result is in agreement with the previously discussed XRD patterns. Further, the Raman vibration of $\mathrm{E}_{1}(\mathrm{LO})$ mode shifted from $565 \mathrm{~cm}^{-1}$ of seed layer and $\mathrm{AZO}$ to $581 \mathrm{~cm}^{-1}$ of $\mathrm{ZnO} / \mathrm{AZO}$. $\mathrm{E}_{1}(\mathrm{LO})$ mode can be related to the lattice defect (oxygen vacancy). 


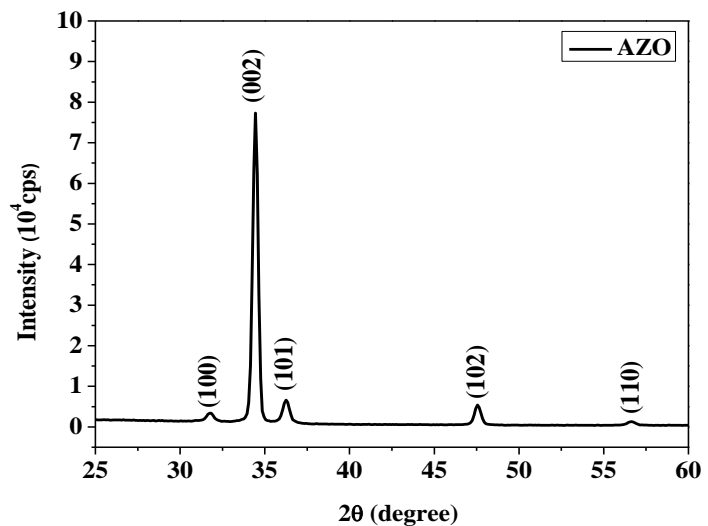

(a)

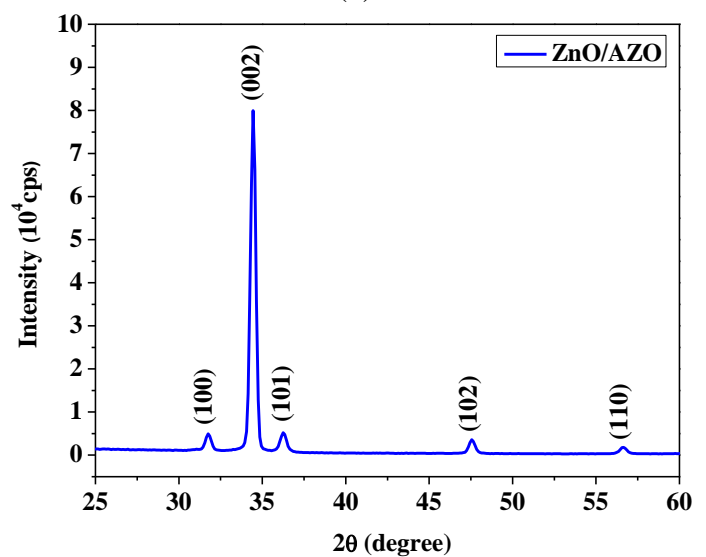

(c)

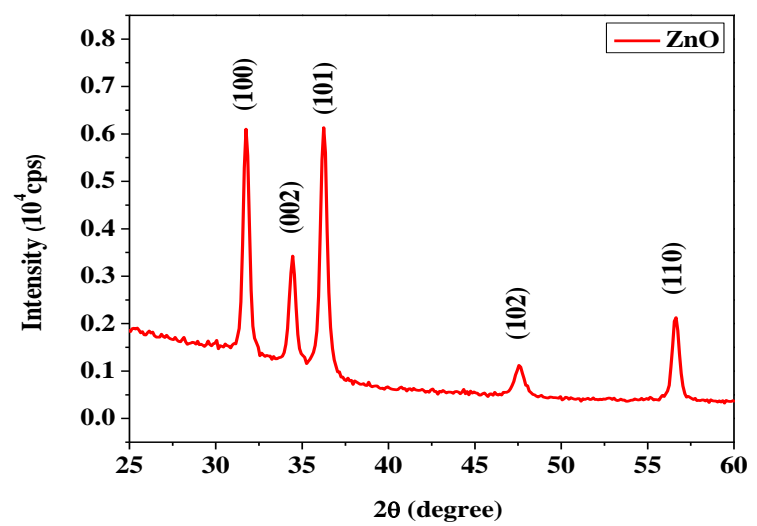

(b)

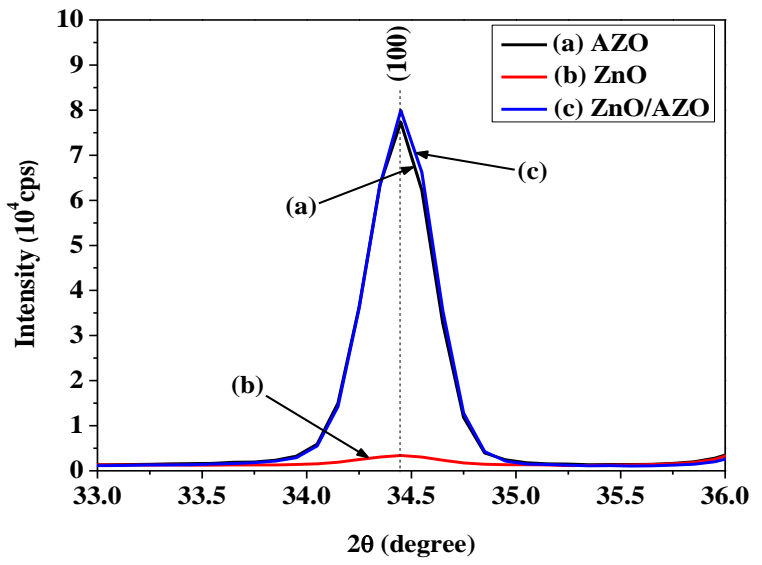

(d)

Figure 3. XRD pattern of (a) AZO, (b) $\mathrm{ZnO}$ and (c) $\mathrm{ZnO} / \mathrm{AZO}$ films

The optical properties of the films were measured using UV-vis spectrophotometer in the wavelength range of $350-800 \mathrm{~nm}$. Figure 5 depicts the transmittance measurement of the films. All films exhibit good optical transparency in the visible region and steep edge around $380 \mathrm{~nm}$, represent the band gap energy of the $\mathrm{ZnO}$. The average transmittances of each film are $94.4 \%, 87.8 \%$, and $66.5 \%$ for seed layer, $\mathrm{AZO}$ and $\mathrm{ZnO} / \mathrm{AZO}$ homojunction films, respectively. The seed layer film possessed the lowest transmittance may be due to the lowest thickness compared to other films. Similar to other film, the variation of average transmittance is expected from the difference in film thicknesses, which is the cause for optical scattering effect [12].

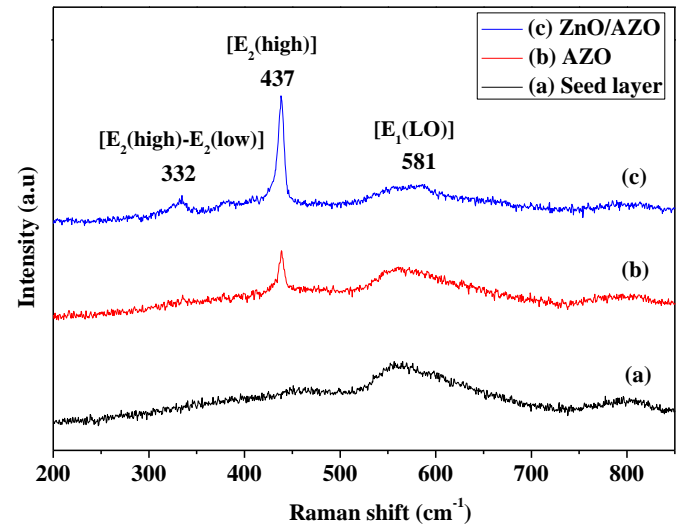

Figure 4. Raman spectra of (a) seed layer, (b) AZO and (c) $\mathrm{ZnO} / \mathrm{AZO}$ films

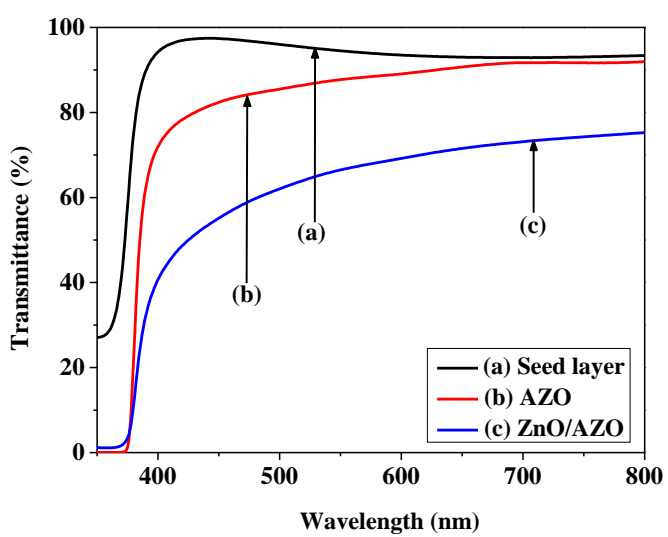

Figure 5. Transmittance spectra of (a) seed layer, (b) $\mathrm{AZO}$ and (c) $\mathrm{ZnO} / \mathrm{AZO}$ films 
From the transmittance plot, the absorption coefficient of the films was plotted using the following Equation [13]:

$$
a=\frac{1}{t} \ln \left(\frac{1}{T}\right)
$$

Here, $\alpha$ is the absorption coefficient, $t$ is the thickness, and $T$ is the transmittance. The absorption coefficient is shown in Figure 6. The films show good absorption at UV region, with $\mathrm{ZnO} / \mathrm{AZO}$ homojunction film possessed the highest UV absorption compared to other samples. The possible reason which leads to this result is high scattering effect at the homojunction interface which causes more photon trapping in the film.

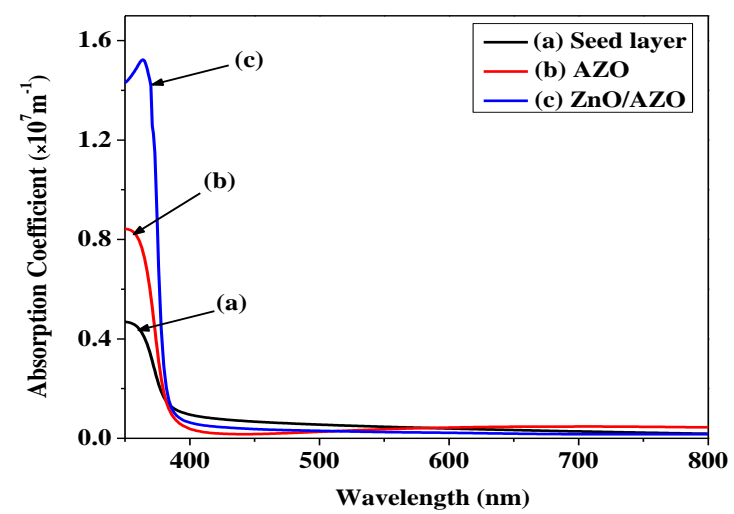

Figure 6. Absorption coefficient of (a) seed layer, (b) AZO and (c) $\mathrm{ZnO} / \mathrm{AZO}$ films

For direct band gap semiconductor, the optical band gap energy, $E_{g}$ can be correlated through the given formula [14]:

$$
a h v=B\left(h v-E_{g}\right)^{\frac{1}{2}}
$$

Here, $B$ is a constant and $h v$ is the incident photon energy. Figure 7 demonstrates the $(\alpha h v)^{2}$ versus photon energy for $E_{g}$ estimation. The $E_{g}$ of the seed layer, AZO and $\mathrm{ZnO} / \mathrm{AZO}$ are 3.26, 3.27, and $3.22 \mathrm{eV}$, respectively. No significant changes to the $E_{g}$ can be observed. However, one the interesting alteration to the $E_{g}$ is when the intrinsic $\mathrm{ZnO}$ is used on the film. We can see that the $E_{g}$ shifted to low value for the $\mathrm{ZnO} / \mathrm{AZO}$ homojunction film. This alteration may be appeared due to the intrinsic nature of $\mathrm{ZnO}$ which has $E_{g}$ value from $3.2-3.3 \mathrm{eV}$ [15]. In addition to that, for $\mathrm{ZnO} / \mathrm{AZO}$ film, the decrement of Eg may be caused by the scattering effect at the interface between the oxide homojunction [16].

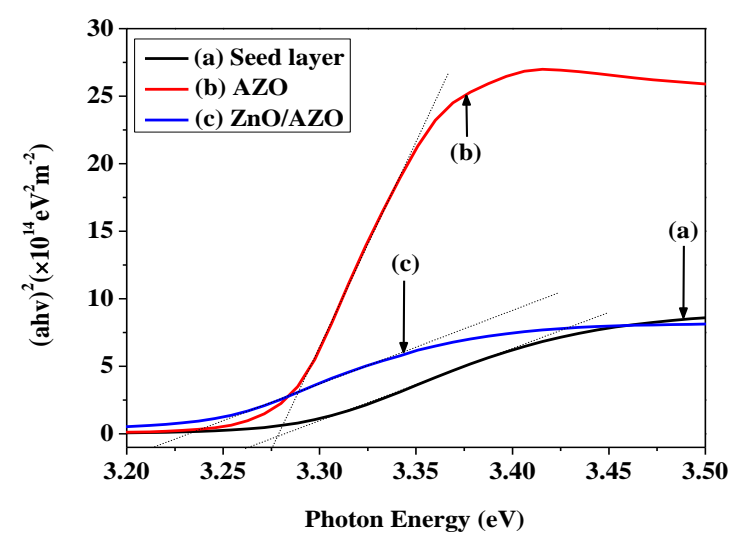

Figure 7. Tauc's plot of (a) seed layer, (b) AZO and (c) $\mathrm{ZnO} / \mathrm{AZO}$ films 


\section{CONCLUSION}

Intrinsic $\mathrm{ZnO} / \mathrm{Al}$-doped $\mathrm{ZnO}(\mathrm{AZO})$ homojunction film was prepared using two-step immersion processes. The FESEM images display that the intrinsic $\mathrm{ZnO}$ film depositions on the seed layer grew into $\mathrm{ZnO}$ nanostructures (nanorods and nanoflakes). However, when the intrinsic $\mathrm{ZnO}$ film is deposited on the nanorod surfaces, it just formed a layer which covered the nanorods of AZO film. The average diameter of the $\mathrm{ZnO} / \mathrm{AZO}$ homojunction also increased up to $95 \mathrm{~nm}$, higher than bare AZO. The XRD patterns demonstrate that the films possessed good crystallinity. AZO and $\mathrm{ZnO} / \mathrm{AZO}$ homojunction films showed preferred orientation at (002) plane while $\mathrm{ZnO}$ film shows preferential growth along (100) and (101) plane orientations. Raman measurement confirms that the films consist of hexagonal $\mathrm{ZnO}$ structure with vibration peaks occurred at $2 \mathrm{E}_{2}(\mathrm{M}), \mathrm{E}_{2}(\mathrm{high})$, and $\mathrm{E}_{1}(\mathrm{LO})$. The $\mathrm{ZnO} / \mathrm{AZO}$ homojunction film possessed excellent absorption at UV region with optical band gap energy of $3.22 \mathrm{eV}$. These results indicate that the $\mathrm{ZnO} / \mathrm{AZO}$ homojunction film has a good potential for optical-based device such a UV sensor.

\section{ACKNOWLEDGEMENTS}

This work was supported by the ASEAN-India Research \& Training Fellowship (IMRC/AISTDF/R\&D/P-1/2017). The authors also would like to thank the Faculty of Electrical Engineering of UiTM for their financial support of this research.

\section{REFERENCES}

[1] Kokate SK, Supekar AT, Baviskar PK, Palve BM, Jadkar SR, Mohite KC, Pathan HM. CdS sensitized pristine and $\mathrm{Cd}$ doped $\mathrm{ZnO}$ solar cells: Effect of SILAR cycles on optical properties and efficiency. Materials Science in Semiconductor Processing. 2018; 80: 179-183.

[2] Voss T, Waldvogel SR. Hybrid LEDs based on $\mathrm{ZnO}$ nanowire structures. Materials Science in Semiconductor Processing. 2017; 69: 52-56.

[3] Ismail AS, Mamat MH, Yusoff MM, Malek MF, Zoolfakar AS, Rani RA, Suriani AB, Mohamed A, Ahmad MK, Rusop M. Enhanced humidity sensing performance using Sn-Doped $\mathrm{ZnO}$ nanorod Array/SnO2 nanowire heteronetwork fabricated via two-step solution immersion. Materials Letters. 2018; 210: 258-262.

[4] Jiang L, Huang K, Li J, Li S, Gao Y, Tang W, Guo X, Wang J, Mei T, Wang X. High carrier mobility low-voltage $\mathrm{ZnO}$ thin film transistors fabricated at a low temperature via solution processing. Ceramics International. 2018; 44(10): 11751-11756

[5] Urgessa ZN, Botha JR, Tankio Djiokap SR, Coleman C, Bhattacharyya S. Patterned growth of ZnO nanorods by chemical bath deposition. Physica B: Condensed Matter. 2018; 535: 79-83.

[6] Nava Núñez MY, Martínez-de la Cruz A. Nitric oxide removal by action of ZnO photocatalyst hydrothermally synthesized in presence of EDTA. Materials Science in Semiconductor Processing. 2018; 81: 94-101.

[7] Mamat MH, Malek MF, Hafizah NN, Md Sin ND, Saurdi I, Suriani A.B, Nafarizal N, Ahmad MK, Rouhi J, Rusop M. Fabrication of Intrinsic Zinc Oxide-Coated, Aluminium-Doped Zinc Oxide Nanorod Array-Based Ultraviolet Photoconductive Sensors. Applied Mechanics and Materials. 2015; 773-774: 696-700.

[8] Jiang M, Tang K, Yan X. Characterization of Intrinsic ZnO Thin Film Deposited by Sputtering and Its Effect on CuIn1-xGaxSe2 Solar Cells. Journal of Photonics for Energy. 2012; 2(1): 28502.

[9] Mamat MH, Sahdan MZ, Khusaimi Z, Ahmed AZ, Abdullah S, Rusop M. Influence of doping concentrations on the aluminum doped zinc oxide thin films properties for ultraviolet photoconductive sensor applications. Optical Materials. 2010; 32(6): 696-699.

[10] Wang M, Ren F, Zhou J, Cai G, Cai L, Hu Y, Wang D, Liu Y, Guo L, Shen S. N Doping to ZnO Nanorods for Photoelectrochemical Water Splitting under Visible Light: Engineered Impurity Distribution and Terraced Band Structure. Sci. Rep. 2015; 5: 12925.

[11] Chanda A, Gupta S, Vasundhara M, Joshi SR, Mutta GR, Singh J. Study of structural, optical and magnetic properties of cobalt doped ZnO nanorods. RSC Advances. 2017; 7(80): 50527-50536.

[12] Ismail AS, Mamat MH, Md. Sin ND, Malek MF, Zoolfakar AS, Suriani AB, Mohamed A, Ahmad MK, Rusop M. Fabrication of hierarchical Sn-doped $\mathrm{ZnO}$ nanorod arrays through sonicated sol-gel immersion for room temperature, resistive-type humidity sensor applications. Ceramics International. 2016; 42(8): 9785-9795.

[13] Lee S-M, Joo Y-H, Kim C-I. Influences of film thickness and annealing temperature on properties of sol-gel derived $\mathrm{ZnO}-\mathrm{SnO} 2$ nanocomposite thin film. Applied Surface Science. 2014; 320: 494-501.

[14] Mohamed R, Mamat MH, Ismail AS, Malek MF, Zoolfakar AS, Khusaimi Z, Suriani AB, Mohamed A, Ahmad MK, Rusop M. Hierarchically assembled tin-doped zinc oxide nanorods using low-temperature immersion route for low temperature ethanol sensing. J Mater Sci: Mater Electron. 2017; 28(21): 16292-16305.

[15] Ahmed MAM, Mwankemwa BS, Carleschi E, Doyle BP, Meyer WE, Nel JM. Effect of Sm doping ZnO nanorods on structural optical and electrical properties of Schottky diodes prepared by chemical bath deposition. Materials Science in Semiconductor Processing. 2018; 79: 53-60.

[16] Yu S, Ding L, Zheng H, Xue C, Chen L, Zhang W. Electrical and photoelectric properties of transparent Li-doped $\mathrm{ZnO} / \mathrm{ZnO}$ homojunctions by pulsed laser deposition. Thin Solid Films. 2013; 540: 146-149. 